\title{
Engaging Undergraduate Students in Computational Chemistry Research: A Tutorial for New Assistant Professors
}

\author{
K. Aurelia Ball ${ }^{1}$, Kedan $\mathrm{He}^{2}$, and Heidi P. Hendrickson ${ }^{3}$ \\ ${ }^{1}$ Skidmore College \\ ${ }^{2}$ Eastern Connecticut State University \\ ${ }^{3}$ Lafayette College
}

April 28, 2020

\begin{abstract}
In this article, we provide advice and insights, based on our own experiences, for computational chemists who are beginning new tenure-track positions at primarily undergraduate institutions. We each followed different routes to obtain our tenure-track positions, but we all experienced similar challenges when getting started in our new position. In this article, we discuss our approaches to seven areas that we all found important for engaging undergraduate students in our computational chemistry research, including setting up computational resources, recruiting research students, training research students, designing student projects, managing the lab, mentoring students, and student conference participation.
\end{abstract}

Keywords - undergraduate research, computational chemistry, primarily undergraduate institution, tenure-track position, career pathways

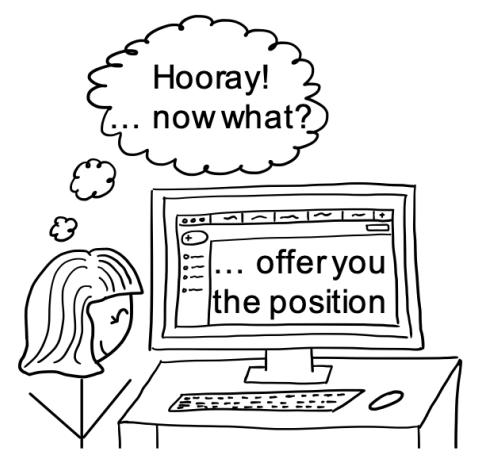

\section{Introduction}

What do you do once you have accepted an offer for a tenure-track faculty position? Figuring out the best way to approach your first tenure-track position can be incredibly exciting, but it's also challenging (and even overwhelming at times). We wrote this perspective on getting started in a tenure-track computational chemistry position at an undergraduate institution based on our own recent experiences. We aim to provide advice and insights to help you figure out what will work best for you as you begin your new tenure-track position. First we'll introduce ourselves, then discuss seven areas that were important to all of us getting started 


\section{Aurelia Ball}

During graduate school, I decided that I wanted to pursue an academic career at a small, primarily undergraduate college. This decision shaped my choice to do a postdoc at UC San Francisco. Before accepting this position, I made sure that my postdoctoral advisor was supportive of my career goals and understanding of me taking time away from research to teach an undergraduate course during my postdoc, and had experience mentoring postdocs in writing successful fellowship grants. During my postdoc, I taught an introductory undergraduate physics course at Santa Clara University (UCSF has no undergraduate students) and received a postdoctoral research fellowship from the NIH in addition to publishing a paper based on my research at UCSF. These activities during my postdoc were key to landing the job as an assistant professor of Chemistry at Skidmore College, as they demonstrated my commitment to undergraduate teaching and my ability to obtain external funding for my research. One surprise in my career path was ending up in a Chemistry department for my tenure-track position. I always expected to be in a Physics department, having completed my undergraduate degree in Physics. However, the position advertised at Skidmore was for a computational chemist who would teach introductory chemistry and physical chemistry. This was a perfect fit for me as my research in computational biophysics studying interactions of intrinsically disordered proteins bridges the disciplines of physics, chemistry, and biology.

\section{Kedan He}

After a one-year Visiting Assistant Professor position at Centre College, I started my current tenure-track position as Assistant Professor of Chemistry at the Eastern Connecticut State University in 2017. Besides gaining valuable teaching experiences at Centre College, I also participated in a collaborative online cheminformatic course involving several Universities and served as a faculty mentor. I became very interested in the application of machine learning and data mining for solving chemistry problems. Now at Eastern, I mainly work with students majoring in Biochemistry, Biology, Health Sciences, and Environmental Earth Sciences. Due to the broad background of students that I have, I've gradually changed my research focus to the application of cheminformatics and machine learning in virtual screening for drug discovery. My current projects are aiming at building the predictive Structure-Activity Relationship (SAR) models for identifying and designing novel small molecules.

\section{Heidi Hendrickson}

I am currently in my third year on the tenure-track at Lafayette College, which is an undergraduate liberal arts college in Easton, PA. When I started graduate school, I knew I wanted to become a professor and pursued opportunities that would help me better understand how students learn. During my Ph.D., I took science education courses in the UM School of Education and participated in a Preparing Future Faculty program. In addition, I was awarded the Sweetland Center for Writing Junior Fellowship, which enabled me to develop and teach a first-year writing composition course focusing on writing in science. I currently teach general and physical chemistry courses in which I implement the Compute-to-Learn (C2L) pedagogy that developed from my M.Sc. work. In C2L, students collaborate to code interactive, instructional demonstrations of physical chemistry topics. Research is a significant aspect of Lafayette culture, and my computational lab focuses on three broad research themes that draw from my graduate and postdoc experience to investigate (1) optoelectronic properties of semiconducting polymers, (2) protein signaling pathways, (3) absorption of solar radiation by atmospheric aerosols. 


\section{Aspects to consider when starting an undergraduate research lab}

\section{Setting up computational resources}

Often, the process of ensuring your lab will have all of the necessary computational resources begins before you get to campus, during the negotiation for your faculty position. It is best to go into the negotiation process with a clear idea of what computational resources you need, based on conversations with other faculty in your field. Adjust the resources you request to the budget of your institution and contact suppliers for a quote. Computational faculty at undergraduate institutions may use their own computers (a cluster or desktop machines), a shared computing cluster, cloud computing resources, or some combination of the above. For example, we all have various research needs and we have found different ways to obtain the necessary resources. Aurelia mainly uses her own cluster at Skidmore College, Heidi mainly uses a shared cluster at Lafayette College, and Kedan mainly uses desktop workstations and cloud computing resources. Be realistic about what resources your research requires, because negotiation is the time when you actually have the opportunity to ask for what you need. In addition to hardware, consider whether you will need administrative support for your machines. New faculty can often spend a large amount of time troubleshooting technical problems, and good staff support can make a huge difference in allowing you to make progress on your research agenda. Talking to people to find shared needs might also help push for administrative investment. For example, at Eastern, research virtual servers are built for faculty across fields who require high-performance computing. Additionally, if you expect to generate large amounts of data, consider resources for properly storing that data including cloud storage options such as AWS.

You may also want to consider what physical research space (if any) you will have on campus where your students can work. Making this a welcoming space for students to spend time and for meeting with your research group can help to foster a collaborative research group culture. If you are using a local computing cluster, it will often be housed in a different space on campus with temperature control where administrative support can access it more easily.

You may also want to apply for external computing resources, such as time on a supercomputer administered by the NSF (XSEDE) or DOE. As members of the MERCURY consortium, we have access to shared computational resources. These external resources can make a big difference for faculty at institutions with limited local computing power or for a particularly resource intensive project. When considering what computational resources to invest in for your lab, keep in mind the ease with which your students can learn to use them and be productive. For example, larger shared clusters may have more computing power but longer queue times depending on the number of users. Large external resources may be challenging for students to learn how to access and use quickly, but may have good support for certain software packages. When purchasing your own hardware, balance price with ease of setup. Some companies offer hardware that is delivered ready to plug in and use, and may already be optimized for a particular software package or application.

\section{Recruiting research students}

Mentoring undergraduate students takes longer than graduate students due to the initial training required for students to learn the necessary knowledge and skills before they can work independently. Undergraduate students are also often involved with a heavy course load and extracurricular activities. Hence a prolonged period is required before they become productive, which makes attracting prospective students early in their first or second year an important aspect to consider when recruiting research students.

Actively seeking out opportunities to participate in prospective student recruitment events enables you to get in contact with students early on. Communicating with admissions and advising offices is also a great way to learn about specific student interests. Several of us actively reach out to other departments that overlap with our research areas, such as physics, criminology, or computer science. Student clubs provide another 
place to interact with prospective research students. For example, Kedan is involved in the Biochemistry club in her department, which is open to students from all majors.

Introductory courses, such as General Chemistry, offer another point of contact with first- and second-year students from different backgrounds and majors. We've found that if you mention your background and expertise in your introduction to the class, students are often intrigued by the idea of conducting chemistry research on a computer. Throughout the semester, Kedan works to connect course material with her research and its broader impact, which allows her to better align her research focus to the various needs and interests of her students.

Another option is a department-wide system for recruiting students to research labs. At Lafayette, students are introduced to chemistry research faculty during a spring recruitment weekend. At Skidmore, the department hosts a research open house in the fall and students fill out a form indicating their research interests. This increases inclusivity for students participating in research, since all students know about this process and the department faculty work together to find positions for most students that apply.

\section{Training research students}

We all use tutorials or mini-courses to initially train students in our labs. When these are designed well, students can seamlessly merge with the research project and quickly become productive. For example, Kedan assigns students' weekly training assignments, where they write a report on assigned reading, then complete a python tutorial which is written to carry out a specific task for the research project. The detailed explanation included in the code allows students to make changes and modify them to be used independently. Students can also contribute to creating training materials. In Aurelia's first semester she had her research students work on formalizing a set of tutorials that are now used by all incoming students to her lab.

We have also taken advantage of workshops such as the MolSSI Undergraduate Education workshops. (TBD, 2020) Aurelia serves as a MolSSI associate and has served as a leader for the MolSSI computational chemistry workshop that is held in conjunction with the MERCURY conference each summer. The MolSSI workshop tutorials are all available online.

\section{Designing student projects}

It can be challenging to develop effective undergraduate student research projects. First of all, what is an "effective" project? In terms of forwarding our research, the student project should be effective in the long run for achieving the broader aims of our research program, but it also must be effective in the short run so that we can publish before tenure. It should be effective in helping student researchers become thorough, thoughtful, and productive scientists, but often must be completed within a brief time period (e.g., a summer program). So, how do we design a project like this? When designing research projects, we didn't worry too much about the duration of the projects. Instead, we all chose to focus on designing projects that can help student researchers become thorough, thoughtful, and productive scientists.

Heidi's approach is to involve each research student in all aspects of their research project, from hypothesis formation to publication. Enabling students to participate, even at a minimum level, in all these aspects helps them gain an appreciation for the overall scientific process while developing the skills required to fully participate as an independent scientist. She initially designed projects that would grow with her students, first incorporating scaffolded calculations that students are able to analyze and evaluate within the context of general chemistry concepts (e.g., protein-ligand docking and intermolecular interactions). Then as students progress through the chemistry curriculum, they require less scaffolding and can carry out a broader range of calculations (e.g., quantum mechanics/molecular mechanics calculations). Heidi has found it helpful to remain flexible in project design to align with student interests. For example, she formed 
multiple collaborations with experimentalists at Lafayette to develop projects that engage students in their specific interests. While it's challenging to manage multiple different undergraduate research projects, the students' passion and dedication to their research projects, plus Heidi's own interest in these areas, makes the effort worthwhile.

Aurelia approaches student projects a bit differently. Projects are designed around a broad research goal developed by the PI (such as a grant aim), and students are assigned parts of these projects based on their skills, interest, and the effort that they can contribute. When new students enter the lab, they are paired with a more experienced student and help on that student's project. Later, as they become more independent, their project changes. This system allows for continuity as different students come and go, since a particular student may graduate before a project is complete. Each semester, students develop a set of goals to work on that term, including both tangible research outcomes and skill-building goals. At the end of the semester students assess their own progress in a written reflection. This allows the PI to adjust students progress and activities to help them build new skills each semester.

\section{Managing the lab}

It is especially important to have deliberate lab management strategy when working with undergraduate students who may only be in your lab for a short amount of time. Several software tools have been helpful to us for managing student progress and keeping track of documents and resources. The first is a digital, and shared, lab notebook. Aurelia uses Evernote in her lab, Kedan uses OneDrive and OneNote, and Heidi uses Google Drive. Evernote and OneNote allow students to create their own notes on their research progress in a shared folder, while other folders are used for general information for the lab, tutorials and methods, and important scientific papers. A "shared drive" in Google Drive can be used in a similar manner. Each of these platforms incorporates shared ownership, which means that students don't have to transfer ownership of their notes, data, or other files to the PI before they graduate. For collaborating on papers and reports, Google documents work well. It can also be helpful for students to update a shared Google spreadsheet weekly with the hours that they spent on research, their activities and the goals for next week. This can allow you to spend less time in meetings just figuring out what students have been doing and more time discussing the science. It also helps students learn to work in a directed way toward a particular research goal. Finally, it helps students gather information for an end-of-term progress report that you could use for grading purposes.

While teaching and running a research lab, your time will be at a premium, so consider how to use it efficiently. Rather than weekly individual meetings with each student, you could meet in subgroups by project, or pair students up who are working together. Ask that students come to these meetings prepared to report on their progress. Full group meetings can be useful for introducing new ideas or working on skills. Give more experienced students the opportunity to lead a meeting on a particular topic, which will also save you time. For quick questions or problems, we find that the Slack messenger is a useful tool. You can create a workspace for your group with different channels. Students can easily ask questions to you and each other, avoiding numerous emails or students getting stuck for days on end. Using Slack to communicate also allows you to be available to your students when you choose, without giving them permission to text you on your personal phone.

\section{Mentoring students}

One aspect of being a new faculty member that you may not have considered is your role in helping your students find their first job after graduation. Many students want to work in a research role for a few years before applying to graduate school, and you can be a valuable resource for finding those types of positions, particularly if they want to continue doing computational work. Reach out to your former colleagues who 
are now in industry and keep a list of people that your students can contact for informational interviews. Encourage students to apply for internships, to attend tours of industrial facilities, and to talk to industry representatives at conferences. For example, there is always one invited speaker from industry at the MERCURY conference. Remind students to use LinkedIn to maintain contact with people they meet at such events.

\section{Student conference participation}

Encouraging students in your research group to present their work at conferences can benefit them (and you) in a number of ways, and we'd like to highlight a few in particular. First of all, it is important to make sure your students participate in the conference they attend, either by presenting a poster or giving a talk. In order to participate in a conference, the student must submit an abstract. We have found that involving students in writing their own abstracts is incredibly beneficial to the student because it helps them to think about their project more broadly than the nitty-gritty details they work with in their daily practice. Reflecting on their work and figuring out how to explain it to other scientists helps them consider the way their work fits into the big picture of general science. It helps them realize that, even though their projects may seem to focus on some minor details of a physical process, they are actually contributing to our global understanding of that process and its relation to the rest of the natural world. When students come to understand how their work contributes to science in general, it can strengthen their sense of belonging in the scientific community.

Conferences are a great way to reinforce that belonging, especially when they are friendly to undergraduate students. For example, we encourage students to present their work at the annual MERCURY undergraduate research conference on computational chemistry. The MERCURY conference includes multiple keynote talks from recognized scientists in academia and industry, who interact with the undergraduate researchers throughout the entire event. Student poster presenters also have the opportunity to give a brief elevator pitch describing their work to the general conference participants before presenting their posters. The interaction between undergraduate researchers and successful scientists has improved the way some of our students perceive their own belonging in STEM fields.

Institutions will often support student presentations at conferences including: National Conferences on Undergraduate Research (NCUR), Poster on the Hill (annual undergraduate poster session on Capitol Hill), and the Annual Biomedical Research Conference for Minority Students.

Students can present at symposia hosted by our own institutions: Annual Research Conference (Eastern Connecticut State University), Skidmore Academic Festival and Summer Research Symposium, and Lafayette Student Research Symposium.

Keep an eye out for local, free conferences, such as (in the northeast): Council of Public Liberal Arts Colleges (COPLAC), New England Science Symposium (NESS), Summit for Women in Stem (Wheaton College), and the New York 6 Undergraduate Research Symposium. If you don't have the funds to send your students to conferences, you can always encourage them to apply for travel awards: The ACS Undergraduate Travel Grant is a competitive award provided by the Graduate Student Symposium Planning Committee, and the ACS Bridge Travel Award is available to support travel for underrepresented students.

\section{Conclusion}

Overall, it's important to remember that, although there are numerous challenges associated with transitioning to a new faculty position, these are also opportunities for you to grow as a researcher and mentor. We 
hope that the experience and advice we've shared in this perspective will help you navigate your transition to a computational chemistry tenure-track position at an undergraduate institution.

\section{Research Resources}

This material is based upon work carried out using MERCURY Consortium computing resources supported by the National Science Foundation under Grant No. CHE-1229354 and CHE-1662030.

\section{Acknowledgements}

K.A.B. and K.H., and H.P.H. thank the MERCURY Consortium for computing resources and technical support. K.A.B. thanks Michelle Osgood and Michael Donnelly for computational support. H.P.H thanks Prof. Chun Wai Liew, Dr. Jason Simms, and Peter Goode, Research Computing System Administrator, at Lafayette College for computational support.

\section{Conflict of interest}

The authors declare no conflict of interest.

\section{Biographies}

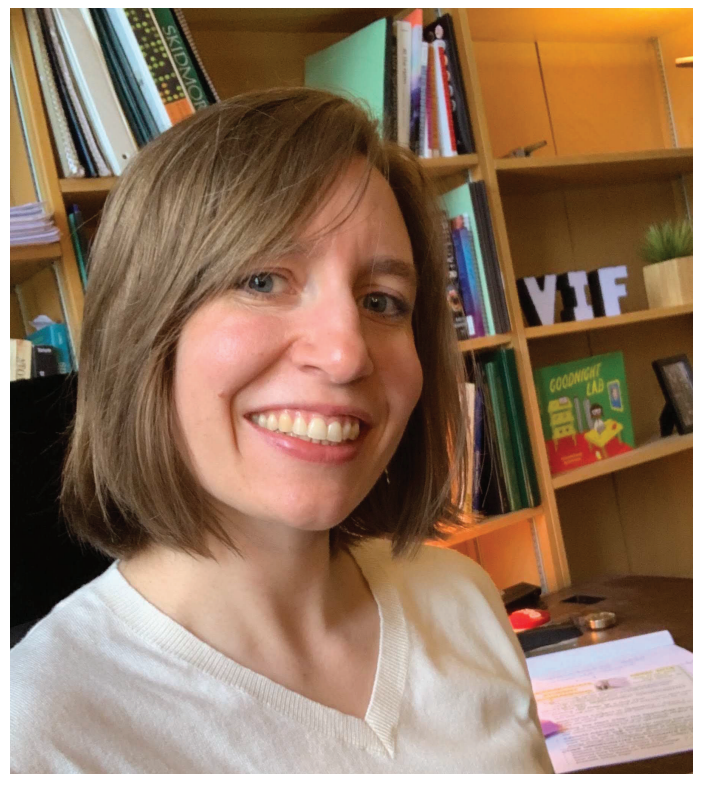

K. Aurelia Ball earned a Ph.D. in Biophysics from the University of California at Berkeley in 2013. She then started a postdoctoral research position at University of California at San Francisco and became an 
NIH National Research Service Award Postdoctoral Fellow in 2015. Prof. Ball started her position as an Assistant Professor of Chemistry at Skidmore College 2016.

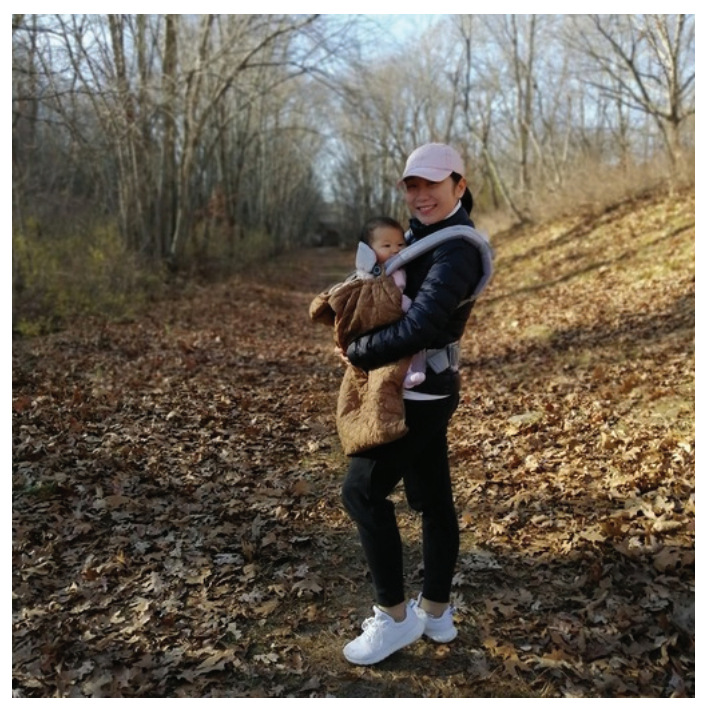

Kedan He earned a M.S. in Materials Science from the University of Alabama in Huntsville in 2009. She earned a Ph.D. in Computational Chemistry from the University of Georgia in 2015. After graduate school, she took a Visiting Assistant Professor position at Centre College. Prof. He started her position as an Assistant Professor of Chemistry at Eastern Connecticut State University in 2017.

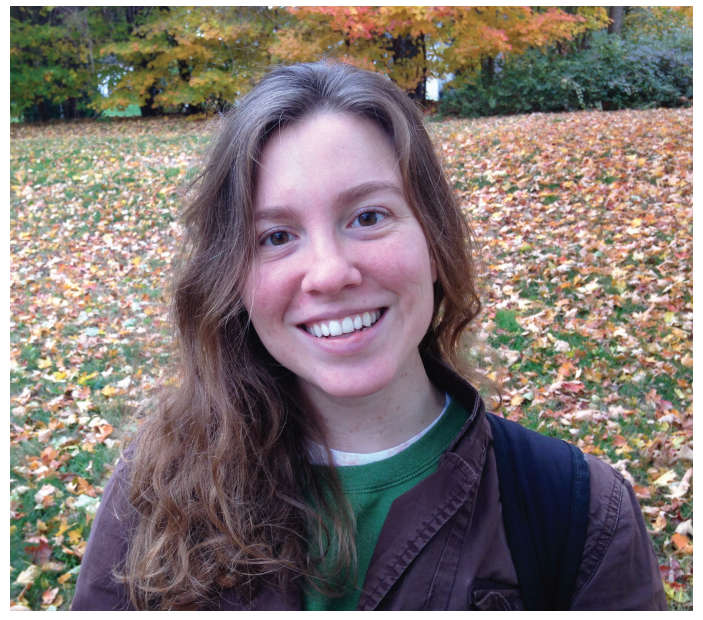

Heidi P. Hendrickson earned a Ph.D. in Chemistry and M.Sc. in Educational Studies at the University of Michigan in 2015. She lectured a summer physical chemistry course at the University of Michigan before moving on to a two-year postdoctoral research position at Yale University. Prof. Hendrickson started her position as an Assistant Professor of Chemistry at Lafayette College in 2017. 


\section{References}

MolSSI Article to be included in current issue. (2020). International Journal of Quantum Chemistry, current volume(TBD), TBD. 